\title{
Parenting Style, Religiosity, Peers, and Adolescent Heavy Drinking
}

Stephen J. Bahr

Brigham Young University - Provo

John P. Hoffmann

Brigham Young University - Provo, john_hoffmann@byu.edu

Follow this and additional works at: https://scholarsarchive.byu.edu/facpub

Part of the Family, Life Course, and Society Commons, Other Sociology Commons, Social Psychology and Interaction Commons, and the Sociology of Religion Commons

\section{Original Publication Citation}

Bahr, Stephen J., and John P. Hoffmann. 2010. “Parenting Style, Religiosity, Peers, and

Adolescent Heavy Drinking." Journal of Studies on Alcohol and Drugs 71(4): 539-543.

\section{BYU ScholarsArchive Citation}

Bahr, Stephen J. and Hoffmann, John P., "Parenting Style, Religiosity, Peers, and Adolescent Heavy Drinking" (2010). Faculty Publications. 3908.

https://scholarsarchive.byu.edu/facpub/3908

This Peer-Reviewed Article is brought to you for free and open access by BYU ScholarsArchive. It has been accepted for inclusion in Faculty Publications by an authorized administrator of BYU ScholarsArchive. For more information, please contact ellen_amatangelo@byu.edu. 


\title{
Parenting Style, Religiosity, Peers, and Adolescent Heavy Drinking*
}

\author{
STEPHEN J. BAHR, PH.D., ${ }^{\dagger}$ AND JOHN P. HOFFMANN, PH.D. \\ Department of Sociology, Joseph F. Smith Building, Brigham Young University, Provo, Utah 84602
}

\begin{abstract}
Objective: The purpose of this research was to examine whether authoritative, authoritarian, indulgent, and neglectful parenting styles were associated with adolescent alcohol use and heavy drinking, after controlling for peer use, religiosity, and other relevant variables. Method: Structural equation modeling was used to estimate direct and indirect associations of parenting style with alcohol use and heavy drinking among 4,983 adolescents in Grades 7-12. Results: Adolescents whose parents were authoritative were less likely to drink heavily than adolescents from the other three parenting styles, and they were less likely to have close friends who used alcohol. In addition, religiosity
\end{abstract}

was negatively associated with heavy drinking after controlling for other relevant variables. Conclusions: Authoritative parenting appears to have both direct and indirect associations with the risk of heavy drinking among adolescents. Authoritative parenting, where monitoring and support are above average, might help deter adolescents from heavy alcohol use, even when adolescents have friends who drink. In addition, the data suggest that the adolescent's choice of friends may be an intervening variable that helps explain the negative association between authoritative parenting and adolescent heavy drinking. (J. Stud. Alcohol Drugs, $71,539-543,2010)$
$\mathrm{I}_{\mathrm{a}}^{\mathrm{N}}$ 2008, 43\% OF HIGH SCHOOL SENIORS had drunk alcohol during the past month, and $28 \%$ reported having been drunk (Johnston et al., 2009). A number of researchers have observed that parenting practices such as support and monitoring tend to deter adolescent alcohol use (King and Chassin, 2004; Patock-Peckham and Morgan-Lopez, 2006, 2009), whereas others have found that parenting practices have little impact after controlling for peer influences (Bahr et al., 1998; Dubow et al., 2008). Similarly, the research on religiosity and adolescent alcohol use has produced inconsistent results (Bahr and Hoffmann, 2008). The purpose of this research was to overcome limitations of existing research by examining the extent to which four different parenting styles, religiosity, and peers are associated with adolescent alcohol use and heavy drinking.

\section{Parenting style}

Based on combined levels of support and control, Baumrind $(1967,1991)$ and Maccoby and Martin (1983) identified four parenting types: authoritative, authoritarian, indulgent, and neglectful. Authoritative parents tend to be high on support (warmth, nurturance) and control (monitoring, discipline). They are demanding but also responsive and warm. Authoritarian parents tend to be high on control but low on

Received: August 27, 2009. Revision: January 13, 2010.

*This research was supported by Brigham Young University.

${ }^{\dagger}$ Correspondence may be sent to Stephen J. Bahr at the above address or via email at: stephen_bahr@byu.edu. support. Their assertions and demands are not balanced with praise and warmth. Indulgent parents tend to be warm and supportive but provide relatively low levels of monitoring and direction. Finally, neglectful parents are low in both direction and warmth.

Children with authoritative parents tend to be higher on various dimensions of social competence than children who experience the other three parenting types (Gray and Steinberg, 1999; Steinberg et al., 1994). Although a number of scholars have studied how support and control influence alcohol use, most have not examined both parenting styles and peer influences simultaneously (Barnow et al., 2002; King and Chassin, 2004; Patock-Peckham and Morgan-Lopez, 2006, 2009; van der Vorst et al., 2006; Walls et al., 2009).

\section{Adolescent religiosity and alcohol use}

There is a growing body of research showing that adolescents who attend religious services regularly are somewhat less likely to use various drugs than those who do not (Bahr and Hoffmann, 2008; Wallace et al., 2007). However, there continues to be debate about the role of religiosity in the etiology of adolescent alcohol and drug use (Baier and Wright, 2001; Wallace et al., 2007). A key issue is whether individual religious involvement has an association with adolescent alcohol use after controlling for peer use and family characteristics (Walker et al., 2007).

\section{Research objectives}

The primary objective of this research was to use structural equation modeling to estimate the associations of par- 
enting style, religiosity, and peer alcohol use with adolescent alcohol use and heavy drinking. Our dependent variable was three levels of adolescent alcohol use: (a) no alcohol use, (b) alcohol use but no heavy drinking, and (c) heavy drinking. Because age, gender, race, parental education, and family structure have been found to be associated with adolescent alcohol use, each was included as a control variable.

\section{Method}

\section{Sample}

The data were from a multistage probability sample collected in an intermountain state in 1997 from 4,983 students in Grades 7-12. The final sample was $82 \%$ of the total number of students enrolled in the sample classrooms at the time of the survey. The respondents ranged from 12 to 19 years old, $51 \%$ were girls, and $71.5 \%$ lived with both of their parents. Thirteen percent lived in a single-parent home, $11 \%$ with the mother and $2 \%$ with the father. Eleven percent lived with one parent and a stepparent, $9 \%$ in a mother-stepfather home and $2 \%$ in a father-stepmother home. Forty-two percent of the fathers and $35 \%$ of the mothers had graduated from college, respectively. Eighty-seven percent indicated that they were White and not of Hispanic origin.

\section{Measurement}

We combined responses from two questions about pastmonth frequency of alcohol use and heavy drinking to create three categories of alcohol use: (a) no alcohol use, (b) alcohol use but no heavy drinking, and (c) heavy drinking. The question on heavy drinking asked how many times they had five or more alcoholic drinks in a row.

Parental support was the sum of three items about parental recognition and praise (range: $0-9, \alpha=.85$ ). Parental control was the sum of five questions about parental monitoring and knowledge of the adolescent's activities (range: 0-15, $\alpha=.75$ ). Control and support were divided at the median to construct Baumrind's (1991) four parenting types. Those parents who were categorized as neglectful were low on both control and support, indulgent parents were low on control and high on support, and authoritarian parents were high on control and low on support; authoritative parents were high on both control and support.

Religiosity was the mean of two questions on frequency of religious service attendance and importance of religion $(\gamma$ coefficient of association $=.82)$. To measure peer alcohol use, students were asked how many of their four best friends had drunk alcohol during the past year. The control variables included age, gender, race, parental education, and family structure. Parental education was measured using the highest level of education by a parent and was coded on a scale from 0 to $5(4=$ completed college and $5=$ graduate or profes-
TABLE 1. Descriptive statistics

\begin{tabular}{|c|c|c|c|c|}
\hline Variable & $M$ or $\%$ & $S E$ & Min. & Max. \\
\hline \multicolumn{5}{|l|}{ Alcohol use, past 30 days } \\
\hline No alcohol use & $80.4 \%$ & 1.3 & & \\
\hline Alcohol use, no heavy drinking & $10.4 \%$ & 0.7 & & \\
\hline Heavy drinking & $9.2 \%$ & 0.9 & & \\
\hline \multicolumn{5}{|l|}{ Parenting style } \\
\hline Authoritative & $29.0 \%$ & 1.1 & & \\
\hline Authoritarian & $12.7 \%$ & 0.7 & & \\
\hline Indulgent & $18.6 \%$ & 0.8 & & \\
\hline Neglectful & $39.7 \%$ & 1.4 & & \\
\hline Religiosity of youth ${ }^{a}$ & 4.4 & 0.7 & 0 & 6 \\
\hline Peer alcohol use ${ }^{b}$ & 1.14 & 0.7 & 0 & 4 \\
\hline \multicolumn{5}{|l|}{ Control variables } \\
\hline Age & 15.07 & 0.16 & 12 & 19 \\
\hline Gender, male & $49.1 \%$ & 1.4 & 0 & 1 \\
\hline White vs. non-White & $87.4 \%$ & 1.2 & 0 & 1 \\
\hline Lives with two parents & $71.5 \%$ & 1.4 & 0 & 1 \\
\hline Parental education & 3.54 & 0.44 & 0 & 5 \\
\hline
\end{tabular}

Notes: All estimates are based on weighted data. The standard errors are adjusted for the multistage sampling design of the survey. Multiple imputation with five replications was used to adjust for missing values. The sample size is 4,983 . ${ }^{a}$ Religiosity reflects the mean of frequency of attendance and importance of religion; ${ }^{b}$ peer alcohol use $=$ mean number of four best friends who drink.

sional school after college). Descriptive statistics based on weighted data for all variables are shown in Table 1.

\section{Analysis}

To compensate for any missing data, we used a random imputation process that resulted in five imputed data sets. The models were then estimated on these five data sets and summarized using standard procedures (Acock, 2005). To adjust for nesting of students within schools, we designated schools as clusters in the models. Sampling weights were used to compensate for oversampling of some groups.

Because heavy drinkers were a subset of alcohol users, it was not appropriate to analyze these two outcomes separately. Rather, we examined alcohol but no heavy use or heavy alcohol use simultaneously in a categorical structural equation model (SEM) with multinomial logistic regression (Hoffmann, 2004). The coefficients represented the log-odds of each outcome - alcohol use or heavy drinking - for each group versus the log-odds of no alcohol use. Because peer alcohol use was a continuous variable, we estimated it using a linear regression model within the full SEM. All coefficients are fully standardized to make comparisons across the implicit models easier.

We computed four different SEMs that allowed a combination of continuous and categorical variables with robust standard errors that were adjusted for the multistage sampling design of the survey (Finney and DiStefano, 2006; Yuan and Bentler, 2000). First, we estimated a model that included only the direct associations of the control variables with parenting style and religiosity, the direct associations of parenting style and religiosity with peer alcohol use, and 


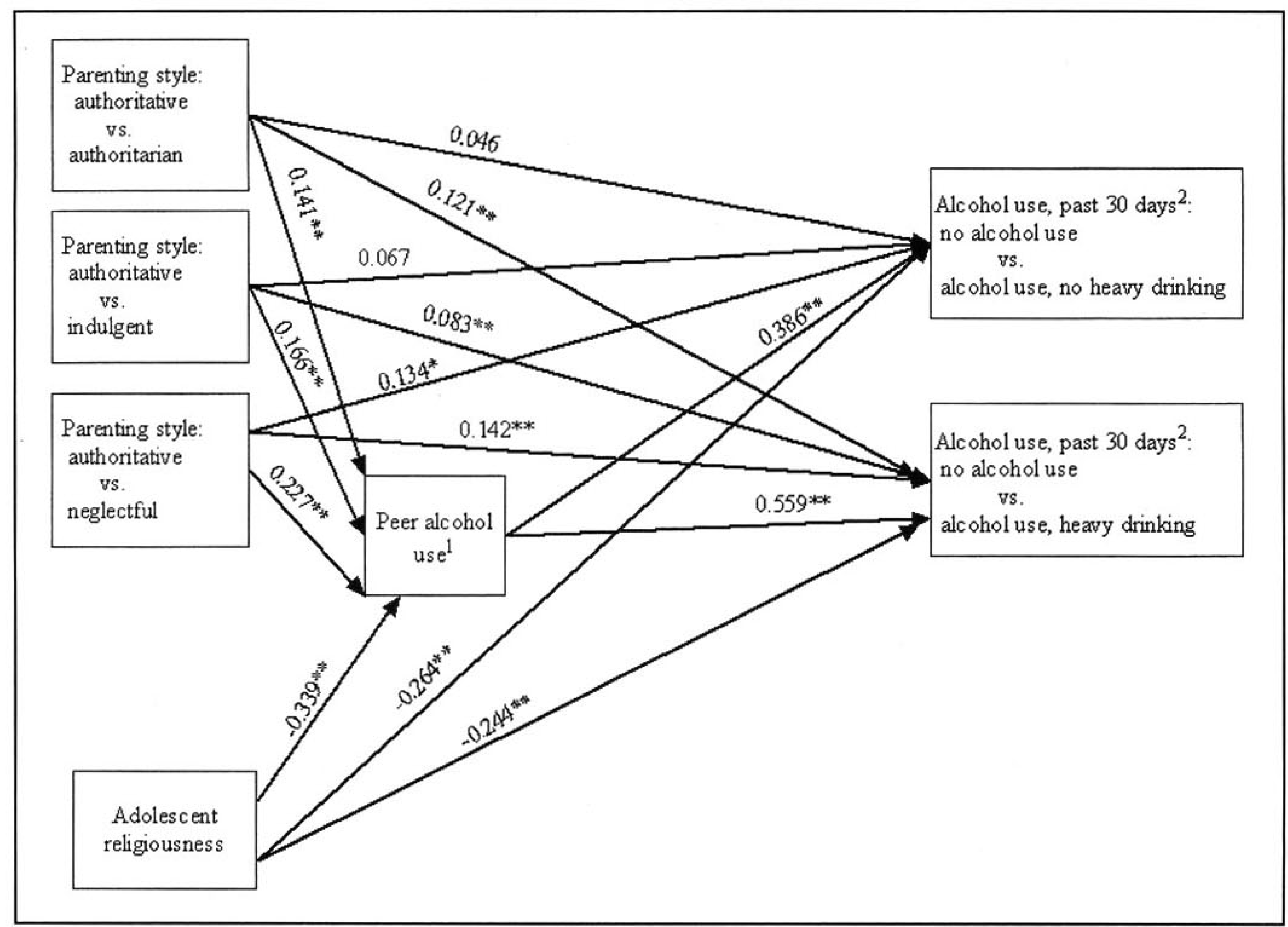

FiguRE 1. Model of parenting style, peer alcohol use, and adolescent alcohol use. All estimates are based on weighted data. The model is estimated with a maximum likelihood procedure that used the expectation-maximization algorithm with Monte Carlo integration (see Enders, 2001). Robust standard errors that are adjusted for the multistage design of the survey are used to estimate $p$ values. Multiple imputation with five replications is used to adjust for missing values. The effects of the control variables are omitted from the model. The sample size is 4,983. 'The coefficients predicting peer alcohol use are standardized linear regression coefficients; ${ }^{2}$ the coefficients predicting the two types of alcohol use are fully standardized log-odds ratios.

${ }^{*} p<.05 ;{ }^{* *} p<.01$.

the direct associations of peer alcohol use with heavy drinking. In the second model, we added the direct associations of parenting style and religiosity with heavy drinking. Third, we added the direct associations of the control variables with peer alcohol use and adolescent alcohol use. Fourth, we estimated a trimmed model that removed all nonsignificant control variable coefficients.

\section{Results}

Figure 1 provides the key results from the final SEMs (full results are available from the authors). When adolescents had close friends who used alcohol, they were significantly more likely to have used alcohol without heavy drinking than adolescents whose friends did not drink, and they were more likely to have participated in heavy drinking. It also appears that the associations were stronger for heavy drinking than for alcohol use without heavy drinking (see Figure 1; fully standardized log-odds 0.559 vs. 0.386 [ $\log$ odds 1.137 vs. 0.635 ]; difference in coefficients: $p<.05$ ).

After controlling for peer and family variables, adolescents who reported religious involvement were less likely to have participated in alcohol use or heavy drinking than adolescents who reported less religious involvement (fully standardized log-odds -0.264 and $-0.244, p<.01$ ). The findings were similar regardless of the type of alcohol use. Religious youth also were significantly less likely to have friends who used alcohol than youth who were not as involved religiously (standardized coefficient $=-0.339, p<.01$ ).

Contrary to expectations, adolescents with authoritarian or indulgent parents did not have higher odds of alcohol use than adolescents with authoritative parents. However, adolescents from neglectful families (low support and low control) were more likely than adolescents from authoritative families 
to have used alcohol without heavy drinking (fully standardized log-odds $=0.134, p<.05$ ). As expected, adolescents from authoritative homes were significantly less likely than adolescents from the other three types to have participated in heavy drinking or to have close friends who used alcohol.

\section{Discussion}

A major finding of this study was that adolescents whose parents were authoritative were less likely to drink heavily than adolescents who experienced the other three parenting styles. We found that this result held after controlling for peer associations, religiousness, and several background variables.

Another important finding was that religiosity was negatively associated with general alcohol use and with heavy drinking. This finding is consistent with the hypothesis that religious involvement may be useful in deterring heavy drinking. Furthermore, the data suggest that the combination of parenting style and religiosity might help counter the influence of peers toward heavy alcohol use (Bahr and Hoffmann, 2008; Baier and Wright, 2001; Wallace et al., 2007).

There were three major limitations of our study. First, because the sample was cross sectional, we were not able to account for possible reciprocal relationships among parenting type, religiosity, peer use, and adolescent alcohol use. Although theory and other research indicate that the influences are in the causal direction proposed in our model, longitudinal data are needed to explore reciprocal paths among parenting styles, religiosity, peer alcohol use, and adolescent alcohol use.

Second, adolescent reports of parental support and control may not reflect the actual behavior of parents. However, adolescent perceptions of parental behavior appear to be as important in adolescent development as the actual behavior of parents (Gray and Steinberg, 1999).

Third, data limitations prevented us from examining the direct involvement of parents in promoting adolescent alcohol use. Other research has shown that the risk of adolescent alcohol use increases if parents use alcohol or have permissive attitudes toward alcohol and drug use (Hawkins et al., 1992). It would be helpful to explore how parental attitudes and behavior toward alcohol use influence adolescent alcohol use within the context of differing parenting styles.

In conclusion, authoritative parents tend to be highly demanding and highly responsive. They monitor their children closely and provide high levels of support and warmth. Our data suggest that peer encouragement to drink might have less impact when parents are both highly supportive and highly attentive. Our findings are consistent with the hypothesis that authoritative parenting may help diminish the likelihood that adolescents will choose risky forms of use such as heavy drinking, even when they have friends who use alcohol or other drugs. These findings have practical implications regarding what parents can do to help insulate their children from peer pressures that encourage heavy drinking. More generally, they suggest that parents can be a significant influence on the risk-taking behaviors of their adolescents.

\section{Acknowledgments}

We are grateful for the contributions of our research team, particularly Cassandra Dorius, Howard Christensen, Suzanne Maughan, Landan Sego, and Xiaoyan Yang.

\section{References}

Acock, A. C. (2005). Working with missing values. Journal of Marriage and Family, 67, 1012-1028.

Bahr, S. J., \& Hoffmann, J. P. (2008). Religiosity, peers, and adolescent drug use. Journal of Drug Issues, 38, 743-770.

Bahr, S. J., Maughan, S. L., Marcos, A. C., \& Li, B. (1998). Family, religiosity, and the risk of adolescent drug abuse. Journal of Marriage and the Family, 60, 979-992.

Baier, C. J., \& Wright, B. R. E. (2001). "If you love me, keep my commandments": A meta-analysis of the effect of religion on crime. Journal of Research on Crime and Delinquency, 38, 3-21.

Barnow, S., Schuckit, M. A., Lucht, M., John, U., \& Freyberger, H. (2002). The importance of a positive family history of alcoholism, parental rejection and emotional warmth, behavioral problems and peer substance use for alcohol problems in teenagers: A path analysis. Journal of Studies on Alcohol, 63, 305-315.

Baumrind, D. (1967). Child care practices anteceding three patterns of preschool behavior. Genetic Psychology Monographs, 75, 43-88.

Baumrind, D. (1991). The influence of parenting style on adolescent competence and substance use. Journal of Early Adolescence, 11, 56-95.

Dubow, E. F., Boxer, P., \& Huesmann, L. R. (2008). Childhood and adolescent predictors of early and middle adulthood alcohol use and problem drinking: The Columbia County Longitudinal Study. Addiction, 103, 36-47.

Enders, C. K. (2001). A primer on maximum likelihood algorithms available for use with missing data. Structural Equation Modeling, 8, 128-141.

Finney, S. J., \& DiStefano, C. (2006). Nonnormal and categorical data in structural equation models. In: G. R. Hancock \& R. O. Mueller (Eds.), A second course in structural equation modeling (pp. 269-314). Greenwich, CT: Information Age.

Gray, M. R., \& Steinberg, L. (1999). Unpacking authoritative parenting: Reassessing a multidimensional construct. Journal of Marriage and the Family, 61, 574-587.

Hawkins, J. D., Catalano, R. F., \& Miller, J. Y. (1992). Risk and protective factors for alcohol and other drug problems in adolescence and early adulthood: Implications for substance abuse prevention. Psychological Bulletin, 112, 64-105.

Hoffmann, J. P. (2004). Generalized linear models. Boston, MA: Pearson.

Johnston, L. D., O'Malley, P. M., Bachman, J. G., \& Schulenberg, J. E. (2009). Monitoring the Future national results on adolescent drug use: Overview of key findings, 2008 (NIH Publication No. 09-7401). Bethesda, MD: National Institute on Drug Abuse.

King, K. M., \& Chassin, L. (2004). Mediating and moderated effects of adolescent behavioral undercontrol and parenting in the prediction of drug use disorders in emerging adulthood. Psychology of Addictive Behaviors, 18, 239-249.

Maccoby, E. E., \& Martin, J. A. (1983). Socialization in the context of the family: Parent-child interaction. In: P. H. Mussen (Series Ed.) \& 
E. M. Hetherington (Vol. Ed.), Handbook of child psychology: Vol. 4. Socialization, personality, and social development (4th ed., pp. 1-101). Hoboken, NJ: John Wiley \& Sons.

Patock-Peckham, J. A., \& Morgan-Lopez, A. A. (2006). College drinking behaviors: Mediational links between parenting styles, impulse control, and alcohol-related outcomes. Psychology of Addictive Behaviors, 20, 117-125.

Patock-Peckham, J. A., \& Morgan-Lopez, A. A. (2009). Mediational links among parenting styles, perceptions of parental confidence, self-esteem, and depression on alcohol-related problems in emerging adulthood. Journal of Studies on Alcohol and Drugs, 70, 215-226.

Steinberg, L., Lamborn, S. D., Darling, N., Mounts, N. S., \& Dornbusch, S. M. (1994). Over-time changes in adjustment and competence among adolescents from authoritative, authoritarian, indulgent, and neglectful families. Child Development, 65, 754-770.

van der Vorst, H., Engels, R. C. M. E., Meeus, W., Dekovic, M., \& Vermulst,
A. (2006). Parental attachment, parental control, and early development of alcohol use: A longitudinal study. Psychology of Addictive Behaviors, 20, 107-116.

Walker, C., Ainette, M. G., Wills, T. A., \& Mendoza, D. (2007). Religiosity and substance use: Test of an indirect-effect model in early and middle adolescence. Psychology of Addictive Behaviors, 21, 84-96.

Wallace, J. M., Jr., Yamaguchi, R., Bachman, J. G., O'Malley, P. M., Schulenberg, J. E., \& Johnston, L. D. (2007). Religiosity and adolescent substance use: The role of individual and contextual influences. Social Problems, 54, 308-327.

Walls, T., Fairlie, A. M., \& Wood, M. D. (2009). Parents do matter: A longitudinal two-part mixed model of early college alcohol participation and intensity. Journal of Studies on Alcohol and Drugs, 70, 908-918.

Yuan, K. H., \& Bentler, P.M. (2000). Three likelihood-based methods for mean and covariance structure analysis with nonnormal missing data. Sociological Methodology, 30, 165-200. 